\title{
Video-assisted thoracoscopic surgery lobectomy for lung cancer: the state of art
}

\author{
Roberto Crisci, Mirko Barone, Francesca Gabriele, Luca Procaccini, Gino Zaccagna, William Di \\ Francescantonio, Duilio Divisi
}

Thoracic Surgery Unit, University of L’Aquila, “G. Mazzini” Hospital, Piazza Italia 1, Teramo, Italy

Contributions: (I) Conception and design: All authors; (II) Administrative support: None; (III) Provision of study materials or patients: All authors; (IV) Collection and assembly of data: All authors; (V) Data analysis and interpretation: All authors; (VI) Manuscript writing: All authors; (VII) Final approval of manuscript: All authors.

Correspondence to: Duilio Divisi, MD, PhD. Thoracic Surgery Unit, University of L'Aquila, “G. Mazzini” Hospital, Piazza Italia n.1, 64100 Teramo, Italy. Email: duilio.divisi@aslteramo.it.

\begin{abstract}
Video-assisted thoracoscopic surgery (VATS) lobectomy represents, nowadays, the gold standard for the treatment of early-stage non-small cell lung cancer (NSCLC). This approach provides a viable alternative to open lobectomy, in terms of radical oncological surgery and of low incidence of complications, as a consequence of sustained innovations and improvements, due to the new available technology devices. Aim of the study was to evaluate the benefits and feasibility of such minimally invasive approaches throughout a careful review of the literature.
\end{abstract}

Keywords: Video-assisted thoracoscopic surgery (VATS) lobectomy; non-small cell lung cancer (NSCLC); minimally invasive surgical treatment

Received: 23 July 2018; Accepted: 07 December 2018; Published: 27 December 2018.

doi: $10.21037 /$ shc.2018.12.06

View this article at: http://dx.doi.org/10.21037/shc.2018.12.06

\section{Introduction}

Video-assisted thoracoscopic surgery (VATS) lobectomy, introduced in the early 90's (1), presents the same oncological radicality, a faster postoperative recovery and a significant reduction in overall morbidity when compared to an open approach in early-stage non-small cell lung cancer (NSCLC) patients (2). Wang et al. (3), reporting 828 VATS surgically treated NSCLC patients (average age of $64.5 \pm 10.3$ years) (predominant histological postoperative diagnosis: adenocarcinoma in 686 patients and squamous carcinoma in 109), showed no intraoperative deaths and perioperative mortality of $1.1 \%$ (9 patients). However, 139 patients $(16.8 \%)$ presented postoperative complications (PCs); among these, 69 (8.3\%) suffered major ones, with prolonged air leak (PAL) the most common one. Authors experienced that major postoperative complications (MPCs) influenced a significant reduction in both 3-year and 5-year disease free-survival rates (MPCs vs. no MPCs: $68.2 \%$ vs. $78.7 \%$ and $44.7 \%$ vs. $70.3 \%$; $\mathrm{P}=0.001$, respectively). Wolf et al. (4), throughout a comprehensive data analysis from "The Statewide Planning and Research Cooperative System of New York State Database" and aiming at an evaluation of the benefits and feasibility of VATS lobectomy compared to thoracotomy (3,187 standard vs. 2,318 VATS lobectomy) in order to identify risk factors influencing NSCLC patients' outcome, reported a lower statistically significant incidence of morbidity rate in VATS brace when compared to thoracotomy one ( $31 \%$ vs. $38 \%, \mathrm{P}=0.0001$ ). Moreover, VATS compared to thoracotomy displayed a reduction in hospital stay (4 $v s$. 6 days, $\mathrm{P}=0.0001)$ and perioperative mortality (22 vs. 66 patients, $0.9 \%$ vs. $2.1 \%$; $\mathrm{P}=0.001)$. In this context, Ezer et al. (5) demonstrated VATS lobectomy should also be considered the best surgical strategy in elderly NSCLC stage I-II patients, due to a better postoperative recovery 
function and reduction of complications, minimizing lifethreatening effects from comorbidities on outcomes. In particular, by both a Surveillance, Epidemiology and EndResults (SEER) cancer registries and medical claims files analysis and enrolling 1,185 VATS lobectomy patients, with an average age of $75 \pm 6$ years, and 8,323 patients, with an average age of $74 \pm 5$ years, who underwent lobectomy via thoracotomy, statistically significant differences were observed in morbidity between cohorts; in particular, concerning thromboembolic diseases [odds ratio (OR): 0.60; 95\% CI: 0.48-0.75), cardiovascular complications (OR 0.68; 95\% CI: $0.51-0.90)$ and extra-pulmonary infectious diseases (OR 0.71; 95\% CI: 0.59-0.85). On the contrary, no statistically significant differences were found in regards to postoperative respiratory failure (OR: $0.91 ; 95 \%$ CI: $0.81-$ 1.02). The purpose of the study was to point out advantages and disadvantages of minimally invasive approaches considering different technical innovations proposed.

\section{Discussion}

A significant evolution in VATS lobectomy has been noted over the last years, due to its diffusion, worldwide availability and technical improvements, as far as the adoption and success of learning curve courses. Concerning the latter, ability acquisition is influenced by several factors, such as surgeon skill and center volume. In fact, it is a common belief that a surgeon has to perform at least 100 minor procedures in order to face major resections, which claim a learning curve of about fifty procedures for a standard two-three port approach (6), as well as for an uniportal one. Notwithstanding some technical peculiarities, the method does not excessively deviate from conventional VATS lobectomy in skill acquisition (7) and so making this technique, introduced by Rocco et al. (8) for diagnostic purposes in the early 2000s, a valid alternative to conventional VATS. Gonzalez-Rivas (9) suggests that one of its greatest advantages, to this day, is the chance to use a robotized articulated arm with a stable camera and a wide margin of maneuver, in order to guarantee optimal vision for the operator and, above all, to reach the location of the lesion properly. This technique, performed by extremely expert surgeons, allows to step towards single surgeon VATS. In this case, the articulated arm would allow a constant vision, thanks to its camera and the possibility of the surgeon to move the lung cranially and caudally, by putting the aim of interest at the center of the surgical field. With regards to patient outcome, Chung et al. (10) have conducted a retrospective analysis with the aim to evaluate any differences between uniportal VATS and conventional VATS lobectomy (biportal and triportal), reporting 150 NSCLC patients (90 uni-VATS $v s .60$ conventional VATS). With an overall uni-to-standard conversion rate of $35.55 \%$, no differences in morbidity according to videoassisted approach were found (uniportal $v s$. conventional VATS: $28.3 \%$ vs. $20.0 \%, \mathrm{P}=0.237)$. Furthermore, similar evidences were found concerning operative time (154.13 vs. 159.77 minutes; $\mathrm{P}=0.638$ ), hospital stay (6.95 vs. 8.50 days; $\mathrm{P}=0.071)$, time of removal of pleural drainage $(5.45$ vs. 5.91 days; $\mathrm{P}=0.538)$ and 30 -day mortality rate $(0$ vs. 0$)$, leading author to conclude uniportal VATS lobectomy was as a viable alternative to conventional VATS lobectomy. Similarly, French et al. (11) in a retrospective cohort study including 50 uniportal VATS patients and comparing them to a standard approach, stated the need for conversion to an open approach was minimal in both groups (U-VATS vs. VATS: $4 \%$ vs. $2 \%, \mathrm{P}=0.56)$. No statistically significant differences in the number of staplers used during the operation ( $9 v s .8 ; \mathrm{P}=0.58)$, time of the surgery (154 vs. 146; $\mathrm{P}=0.08)$ and major complications $(20 \%$ vs. $10 \% ; \mathrm{P}=0.26)$. Lin et al. (12), in their retrospective monocentric study on 67 NSCLC patients, have evaluated surgical outcome according to uniportal or biportal VATS approach $(21 \mathrm{vs}$. 46 patients). No statistically significant differences in blood loss $(\mathrm{P}=0.089)$, time of chest tube removal $(\mathrm{P}=0.138)$ and hospital stay $(\mathrm{P}=0.108)$ were found. Postoperative pain was lower in uniportal cohort $(\mathrm{P}=0.05)$; however, time of surgery was significantly higher in the single port group $(132.3 \pm 13.2$ vs. $105.4 \pm 12.5 \mathrm{~min} ; \mathrm{P}=0.012)$. For these reasons, Author concluded favoring uniportal VATS strategy due to equal postoperative morbidity but lower postoperative pain. This aspect should be a cornerstone in decision making towards a minimally invasive approach. In this regard, Louis et al. (13) have carried out a study in a wide number of patients undergoing pulmonary lobectomy, aiming to evaluate some differences in pain management according to videoassisted approach (uniportal vs. multiportal VAT). Enrolling 84 patient (35 uni-VATS vs. 49 conventional VATS), a lower dose of narcotics had been administered in uni-VATS patients when compared to control brace [182.0 vs. 260.0 oral morphine equivalent $(\mathrm{OMEq}) ; \mathrm{P}=0.028]$, especially on first postoperative day (66.0 vs. 112.0 OMEq; $\mathrm{P}=0.024)$. 


\section{Conclusions}

The validity of VATS lobectomy as an alternative surgical strategy to classic lobectomy via thoracotomy has been widely demonstrated, as it provides similar oncological radicality with a better outcome especially for postoperative pain management, morbidities, faster recovery and quicker hospital discharge. Moreover, comparing different approaches, equivalent results have been reported making them considered all valid options for NSCLC surgical treatment. However, conventional VATS approaches should not be overlapped by uniportal ones as being their efficacy and feasibility equivalent. So, the choice for an approach should be considered according to the surgeon's propensity and ability without interfering with patients' outcome and oncological radicality.

\section{Acknowledgments}

Funding: None.

\section{Footnote}

Provenance and Peer Review: This article was commissioned by the editorial office, Shanghai Chest for the series "Surgical Approaches to VATS Lobectomy: Meet the Experts". The article has undergone external peer review.

Conflicts of Interest: All authors have completed the ICMJE uniform disclosure form (available at http://dx.doi. org/10.21037/shc.2018.12.06). The series "Surgical Approaches to VATS Lobectomy: Meet the Experts" was commissioned by the editorial office without any funding or sponsorship. RC served as the unpaid Guest Editor of the series. The authors have no other conflicts of interest to declare.

Ethical Statement: The authors are accountable for all aspects of the work in ensuring that questions related to the accuracy or integrity of any part of the work are appropriately investigated and resolved.

Open Access Statement: This is an Open Access article distributed in accordance with the Creative Commons Attribution-NonCommercial-NoDerivs 4.0 International License (CC BY-NC-ND 4.0), which permits the noncommercial replication and distribution of the article with the strict proviso that no changes or edits are made and the original work is properly cited (including links to both the formal publication through the relevant DOI and the license). See: https://creativecommons.org/licenses/by-nc-nd/4.0/.

\section{References}

1. Hazelrigg SR, Nunchuck SK, LoCicero J 3rd. Video Assisted Thoracic Surgery Study Group data. Ann Thorac Surg 1993;56:1039-43; discussion 1043-4.

2. Cao C, Petersen RH, Yan TD. Learning curve for videoassisted thoracoscopic lobectomy. J Thorac Cardiovasc Surg 2014;147:1727.

3. Wang $\mathrm{S}, \mathrm{Li} \mathrm{X}, \mathrm{Li} \mathrm{Y}$, et al. The long-term impact of postoperative pulmonary complications after video-assisted thoracic surgery lobectomy for lung cancer. J Thorac Dis 2017;9:5143-52.

4. Wolf A, Liu B, Leoncini E, et al. Outcomes for Thoracoscopy Versus Thoracotomy Not Just Technique Dependent: A Study of 9,787 Patients. Ann Thorac Surg 2018;105:886-91.

5. Ezer N, Kale M, Sigel K, et al. Outcomes after Videoassisted Thoracoscopic Lobectomy versus Open Lobectomy for Early-Stage Lung Cancer in Older Adults. Ann Am Thorac Soc 2018;15:76-82.

6. Divisi D, Barone M, Zaccagna G, et al. Video-assisted thoracoscopic surgery lobectomy learning curve: what program should be offered in a residency course? J Vis Surg 2017;3:143.

7. Guerrero WG, González-Rivas D. Multiportal videoassisted thoracic surgery, uniportal video-assisted thoracic surgery and minimally invasive open chest surgeryselection criteria. J Vis Surg 2017;3:56.

8. Rocco G, Brunelli A, Jutley R, et al. Uniportal VATS for mediastinal nodal diagnosis and staging. Interact Cardiovasc Thorac Surg 2006;5:430-2.

9. Gonzalez-Rivas D. Unisurgeon' uniportal video-assisted thoracoscopic surgery lobectomy. J Vis Surg 2017;3:163.

10. Chung JH, Choi YS, Cho JH, et al. Uniportal videoassisted thoracoscopic lobectomy: an alternative to conventional thoracoscopic lobectomy in lung cancer surgery? Interact Cardiovasc Thorac Surg 2015;20:813-9.

11. French DG, Thompson C, Gilbert S. Transition from multiple port to single port video-assisted thoracoscopic anatomic pulmonary resection: early experience and comparison of perioperative outcomes. Ann Cardiothorac 
Surg 2016;5:92-9.

12. Lin F, Zhang C, Zhang Q, et al. Uniportal video-assisted thoracoscopic lobectomy: An alternative surgical method for pulmonary carcinoma. Pak J Med Sci 2016;32:1283-5.

doi: $10.21037 /$ shc.2018.12.06

Cite this article as: Crisci R, Barone M, Gabriele F, Procaccini L, Zaccagna G, Di Francescantonio W, Divisi D. Video-assisted thoracoscopic surgery lobectomy for lung cancer: the state of art. Shanghai Chest 2018;2:101.
13. Louis SG, Gibson WJ, et al. Uniportal video-assisted thoracoscopic surgery (VATS) technique is associated with decreased narcotic usage over traditional VATS lobectomy. J Vis Surg 2017;3:117. 